\title{
A CASE STUDY ON THE OUTBREAK OF PAEDERUS DERMATITIS CAUSED BY ROVE BEETLES (COLEOPTERA: STAPHYLINIDAE) IN WOMEN'S HOSTELS OF EASTERN UNIVERSITY, SRI LANKA
}

\author{
Vinobaba, $\mathrm{M}^{1}$., Kanesharatnam., $\mathrm{N}^{1^{*}}$ and Thamilvannan, $\mathrm{N}^{2}$ \\ ${ }^{1}$ Department of Zoology, Faculty of Science, Eastern University, Sri Lanka \\ ${ }^{2}$ Department of Dermatology, Teaching Hospital, Batticaloa, Sri Lanka
}

\begin{abstract}
Disreputable outbreaks of Paederus dermatitis (PD) has been predominant in women's hostels of Eastern University and its surroundings. This study was undertaken with the objectives of recommending precautions and treatment for students and local residents around the university from 2015-2019. Sampling was done by light traps and hand collection. Photographs of beetles and skin lesions were taken. Hostel surrounding was inspected to find out the breeding sites of beetles. Case review among affected students and staffs was carried out through face to face interview. Approximately, 145 students were principally affected on the exposed body parts of which $95 \%$ of students developed specific symptoms including erythema, edematous plaques with vesicles, micropustules and about $5 \%$ of students reported no specific symptoms. PD was more prevalent during rainy seasons than drought months. The students in women's hostels were more frequently affected than in men's hostels. Population dynamics, seasonal variations, life history and behavior pattern of rove beetles should be thoroughly investigated prior to their control.
\end{abstract}

Keywords: Dermatitis, paederin, rove beetle, Sri Lanka.

*Corresponding author: nilanik@esn.ac.lk

iD https://orcid.org/0000-0002-6070-8989 


\subsection{INTRODUCTION}

Paederus dermatitis (PD) also known as dermatitis linearis is a skin blistering inflammatory lesion caused by vesicating polyketide cytotoxin called paederin released from rove beetles (Paederus sp) belonging to the family Staphyllinidae of Coleoptera [1,2]. This notorious toxin, paederin $\left(\mathrm{C}_{25} \mathrm{H}_{45} \mathrm{O}_{9} \mathrm{~N}\right)$ which is an amide with two tetrahydropyran rings circulating in haemolymph [3], exudes copiously from these beetles while they get crushed on the skin fortuitously causing burning, itching, blistering and erythema on the skin $[4,5,6]$. Recent studies stated that paederin is produced by endosymbionts (Pseudomonas species) inhabiting within Paederus sp. and this vesicant inhibiting mitotic cell division by obstructing DNA and protein synthesis $[7,8]$. In some instances, they release paederin as a defensive action to escape from predators when they are in danger [9]. Paederus species which are nocturnal, predatory beetles, live in moist shady habitats possibly in paddy fields, banks of water bodies and marshes $[10,11,1,12]$ and show positive phototaxic behavior [13] and are inevitably drawn to bright incandescent, fluorescent light and long wave ultraviolet in human residences after dusk [14,15].

Approximately 650 Paederus species are found all over the world except Antarctica of which 50 species have been identified to cause PD [16,17]. Outbreaks of dermatitis linearis have often been reported in tropical countries including Iran, Iraq, India, Pakistan, Sri Lanka and Southeast Asia. In Sri Lanka, first incidence of acute PD was reported among medical staffs on night duties and patients in open wards in Ragama hospital, near Colombo area [18]. Thereafter, no outbreak was reported from Sri Lanka. However disreputable outbreaks of PD have been highly predominant in women's hostels of Eastern University and its surrounding in Vantharumoolai region, Eastern part of Sri Lanka and it was scrutinized from July, 2015-August, 2019. The present study was undertaken to assess epidemiology of PD outbreak, management tactics of infestations and to recommend treatments and precautions for students and local residents around the University.

\subsection{MATERIALS AND METHODS}

Light traps were made at Department of Zoology and installed at balcony side of hostel and surrounding trees for sampling of nocturnal insects at night as in Fig. 1(a)-(c). Traps were switched on after all the lights were switched off from the hostel rooms. Covers of florescent light were also examined for the presence of nocturnal insects.

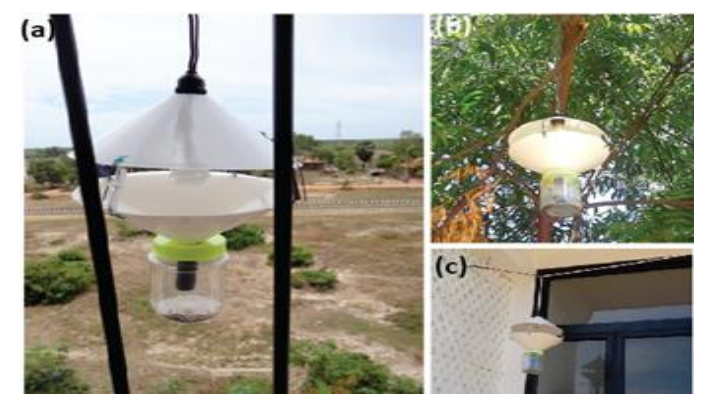

Figure 1: Installation of light traps at (a). outside of balcony, (b). hanging on the trees near to hostels (c). balcony.

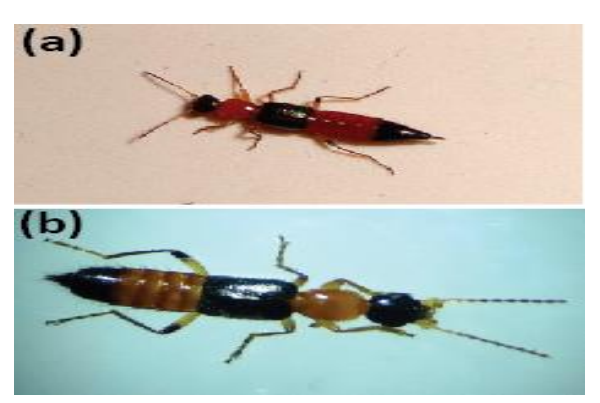

Figure 2: Paederus fuscipes Curtis, 1826 (a). Live beetles on the floor of the wash room, (b). Dead beetle. 
Live beetles were detected and collected on the floor of bath rooms, toilets, corridors, near to waste water discharge, rooms with open windows and study rooms of women's hostels where lights are switched on for long hours during night (Fig.2 (a)). Seasonal variations of beetles collected from light trap sampling was noted from 2015-2019. The specimens were sorted out at the laboratory of Department of Zoology and identified with Kyowa optical SE-L stereomicroscope up to genus level. Hostel front, backyards and bathroom outlet pipes were inspected in order to find out the breeding sites of beetles (Fig. 3(a)-(f)). Case review among affected students and staffs was carried out in order to gather the details of constitutional symptoms, site and type of lesions, sleeping routines, past history of incidences and infrastructure of hostel building through face to face interview. In addition, photographs of beetles and skin lesions caused by them were taken. Treatment of PD was discussed with dermatologist and regional medical officer. Management actions and precautionary measures were instructed to students in hostels.
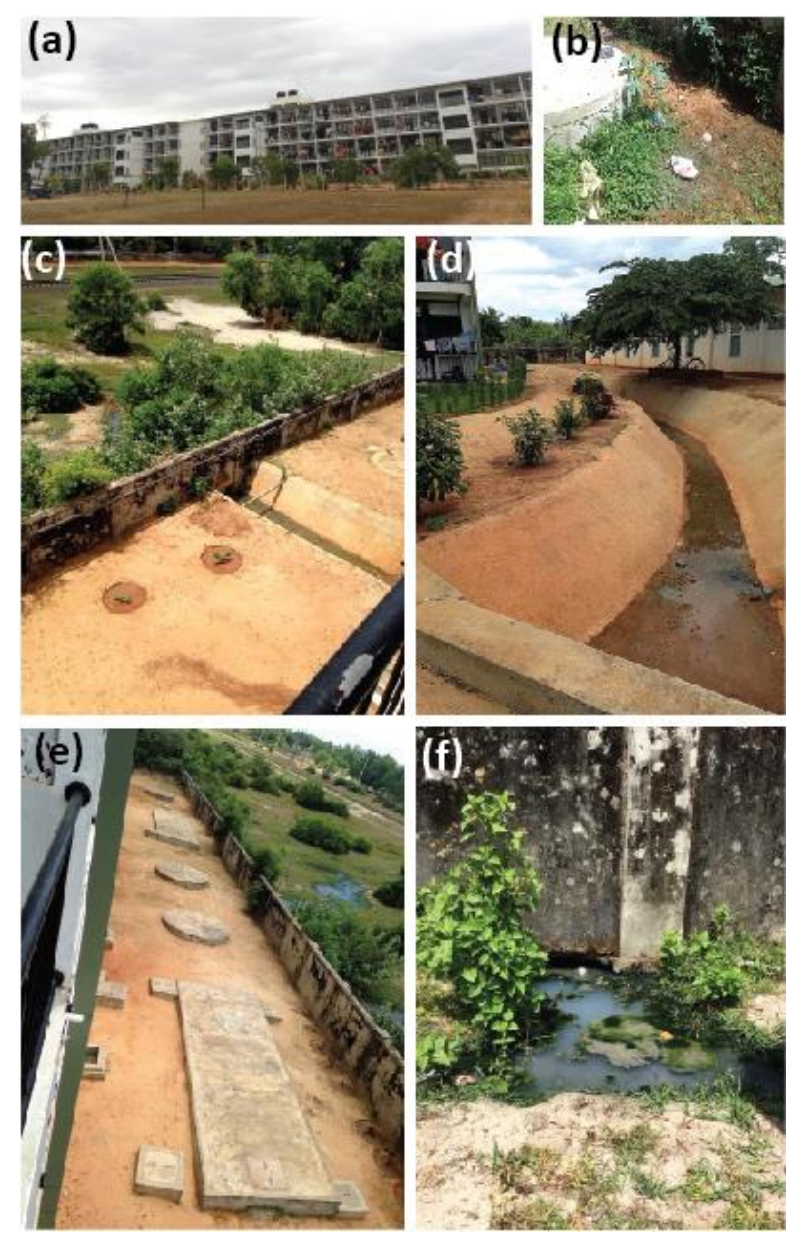

Figure 3: Possible ideal breeding habitats of rove beetles, (a). One of the women's hostel (ICC A and B) of Eastern University, (b). Sanitary pits surrounded with vegetation and garbage at the backyard, (c). Drainage at the hostel backyard, (d). Drainage between women and men's hostels, (e). Hostel backyard near to the vegetation, (f). Waste water discharge at the backyard. 


\subsection{RESULTS}

More than 145 students (24\%) were principally affected on the exposed body parts including face and neck, nape, around eyes, breast, abdomen, fore and hind arms of which $95 \%$ of students experienced sudden onset of severe burning sensation followed by erythema and edematous plaques with centered vesicles and bullae (Fig. 6(a)-(b)), sometimes erythema with micropustules, periorbital oedema (Fig. 4(a)-(c)) without keratoconjunctivitis (Nairobi Eye), whiplash linear lesions (Fig. 4(d)), kissing lesions (Fig. 5(a)-(b)) on knee and elbow, itching, residual hyperpigmentation (Fig. 7(a)-(b)), necrotic crusted lesions (Fig. 8(a)-(b)), desquamation (Fig. 9(a)-(d)), linear crusted lesion (Fig. 10(a)-(b)), erythematous purpuric rash (Fig. 10(c)-(d)) and 5 $\%$ of students reported no specific symptoms. Some students demonstrated acute multiple large lesions on the forehead, neck and breast with confluent epidermal necrosis and experienced systemic symptoms such as fever, vomiting, arthralgia and neuralgia. Ocular lesions could be caused by passive transfer of toxin from affected areas by fingers.

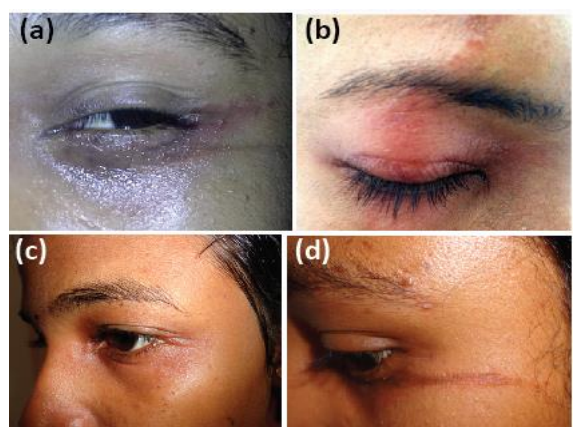

Figure 4: Linear erythematous purpuric lesions on the (a). Periorbital skin, (b). Upper eyelid, (c). Periorbital oedema, (d). Whiplash linear lesion near to eye.

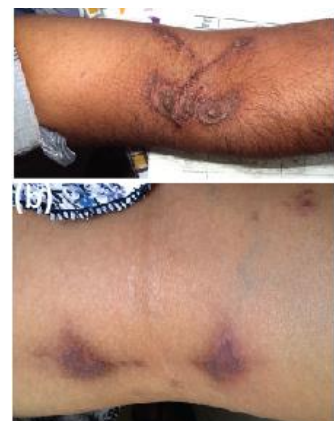

Figure 5: Kissing lesions, (a). Acute kissing lesion with central blister in the elbow when the insect get crusted, (b). Acute erythematosus purpuric kissing lesion in the skin fold.

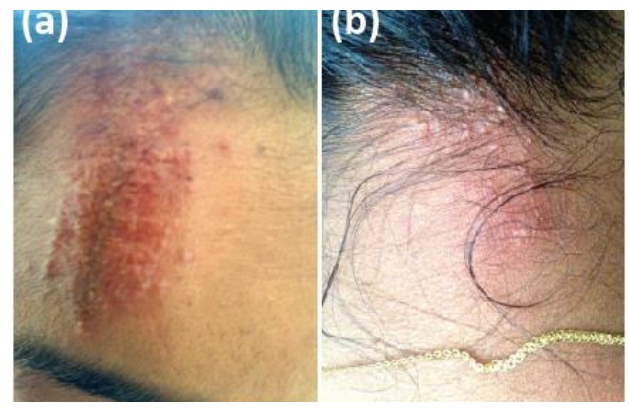

Figure 6: Acute linear erythematous plaque studded with pustules on (a). forehead 


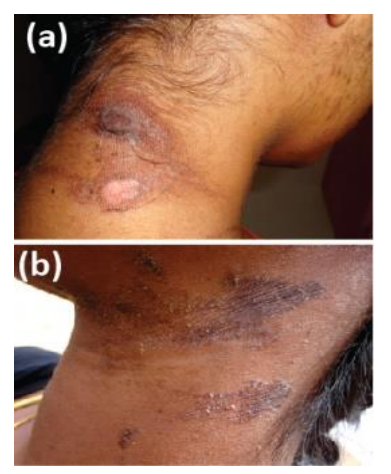

Figure 7: (a)-(b). Erosion, crusting and hyper-pigmentation after rupturing of blisters on the nape and neck.

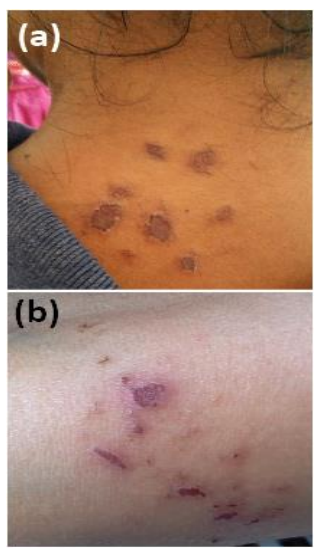

Figure 8: Grouped superficial necrotic crusted lesions on (a). upper back and (b). hand.

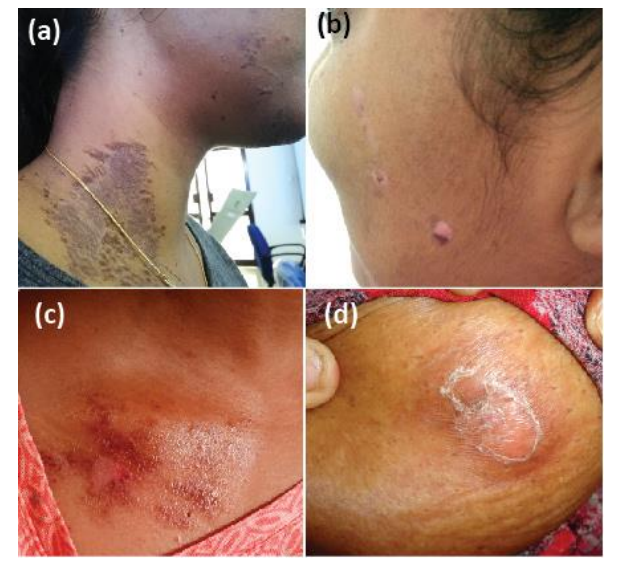

Figure 9: Desquamating lesions on (a). neck, (b). cheek, (c). chest and (d). stomach

Although, the latent period from contact of poison to onset of symptoms was 1-2 days, expression of symptoms was dependent on the person's health conditions. Healing time of acute skin lesions was 10-20 days with residual post-inflammatory hyperchromic scarring that persisted for 6-12 months. In some cases, it persisted more than 2-4 years, thus posing cosmetic issues on the exposed body parts like face, neck, hand among University students (personal communication). However, pigmentation was not observed in mild cases. 


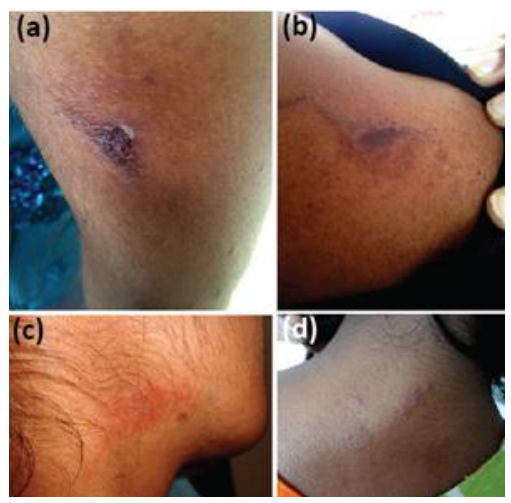

Figure 10: (a)-(b). Linear crusted lesion with early hyperpigmentation, (c)-(d). Linear erythematous purpuric rash on (c). submandibular area and (d). upper back.

It was confirmed that almost all affected students studied under artificial lightings in the study hall at night or slept with opening of windows or balcony door. There was another motive for cause of PD, because these beetles can hide in their clothings, towels and crushed on the skin while wearing the cloths or wiping the face and body with towel (personal communication with victims). The students in women's hostels affected than in men's hostels, this might be because of the occurrence of ideal breeding sites for beetles including waste water discharge (Fig. 3(f), damp, moist habitats, sanitary pits surrounded with vegetations (Fig. 3(b), garbage dumping sites including cooking wastes behind women's hostels (Fig. 3(b), drainage between women and men's hostels (Fig. 3(c)-(d). In addition, PD affected the attendance of students for lectures and practical classess.

\subsection{DISCUSSION}

PD was more prevalent in wet months of the year after rain showers especially June, July, August than dry months due to the moist soil conditions favouring breeding of rove beetles. It was noticed that students in third and fourth floors were severely affected than in ground and first floors in four-storey hostel buildings. This may be due to the flight pattern of rove beetles from surrounding vegetations toward attractive uppermost level luminescent lightings. Previous studies [19,13,20] so proved that victims of PD were in top and middle floor levels compared to the ground level of apartments. Further, large-scale of wind system also facilitate dispersal of agricultural pests or outbreaks of insect-borne infection from long distances [21], thus the rainy months with strong wind blowing may be an feasible climatic factor for PD outbreaks.

Formerly, students and security staffs misinterpreted that bite or sting of beetles causes PD and also blister beetles (vernacularly known as 'fire beetles' in village) was misdiagnosed as a cause of this dermatitis. Blister beetles belonging to family Meloidae are always confused with Paederus beetles, as they also provoke dermatitis or blisters on the skin by releasing a defensive chemical, cantharidin while in danger [11].

Specimens could tentatively be identified as Paederus fuscipes Curtis, 1826 (Fig.2 (a)-(b)), however further study will be needed for proper identification by taxonomic key of Paederus species and genitalic dissection especially shape of aedeagus. P. fuscipes is frequently found in marshes, rice fields, moist vegetations and has a cosmopoliton in distribution from Sri lanka, 
India, Southeast Asia, Central Asia to Japan, to Australia. The brightness of lights from housing areas attracts $P$. fuscipes from their breeding habitats located many miles far-away [13].

PD is commonly ignored by students and local residents, most of them do not consult dermatologists or general physicians, instead, they treat it themselves by applying locally available dermal creams. Consequently, it may lead to misdiagnosis, because the clinical appearance of PD imitates other dermatosis such as herpes zoster, bullous impetigo, phytophotodermatitis, irritant dermatitis provoked by other venomous insects, liquid burns, cantharidin dermatitis $[22,23,13,24,25]$. However, PD is clinically manifested by acute onset eruption with burning pain followed by erythematous plaques with micropustules, linear pattern of dermatitis, early lesions characterized by neutrophilic spongiosis, exocytosis and epidermal reticular degeneration, acute lesions demonstrating intraepidermal vesiculation and confluent epidermal necrosis with comprehensive history about chances for interaction with Paederus beetles or patients from disease epidemiological region [26,1]. Thus, causative agents for dermatitis should properly be identified prior to the treatment.

PD was diagnosed clinically without any specific investigations (tests) based on the affected patient's clinical history including living environment (hostels), previous similar episodes, other inmate's affected, seasonal epidemics etc. Clinical examination is also very important to arrive at the diagnosis. Common treatments for PD are oral analgesic, antihistamines for reducing itching, antibiotics and corticosteroid creams. Topical steroid-antibiotic combination has been prescribed after formation of lesions. In addition, calamine, camphor and topical anesthetics (lidocaine, benzocaine) can be recommended for temporary relief of pruritus and silver sulfadiazine has also been used due to its antibacterial activityn [1,27].

Larvicide (Abate liquid), insecticide (lambda cyhalothrin) were sprayed inside and hostel premises for temporary control of larvae and adults as per entomological officer's instructions, however, infestation was noticed after certain time period. In order to avoid beetle in contact with human residential areas, precautions should be made including shutting of balcony doors and windows by dusk, sealing of windows with fine mesh net, sleeping under a mosquito nets, applying insect repellent creams or oils (cinnamon oil, citronella oil) at nights, clearing weeds, garbages and excess vegetations near hostels, tillage of moist soil around the hostel surrounding, switching off lights near beds, usage of low intensity of lights at night, public and clinical education of etiology $[28,1]$, education of students and staffs to identify Paederus beetles, avoidance of handling beetles by hands, beetles on the skin should be blown off or gently removing by allowing them to walk on the paper [28,9], if accidentally crushed, thorough washing of skin with soap and water as quickly as possible to eliminate pederin, awareness program of PD for students and local residents by issuing leaflets in their native languages, implementation of proper sanitary and waste disposal, indoor application of insecticides (pyrethroid) as mentioned above. 


\subsection{CONCLUSION}

Extensive investigations on the population dynamics, seasonal variations, life history and behavior pattern of rove beetles should be thoroughly studied, in order to reduce PD eruption prior to the implementation of integrative control measures.

\subsection{ACKNOWLEDGEMENTS}

We thank to Dr. Srinath (Medical Officer of Health, Batticaloa District) and Ms. Sinthuja Gnanananthan (Entomological officer, Anti Malaria Campaign, Batticaloa) for providing suggestions, treatment and preventing tactics during PD eruption. We are grateful to Mr. P. Vijayakumar for preparation of light traps and all the staff members of Department of Zoology who helped us for making light traps, sample collection and site evaluation.

\subsection{REFERENCES}

[1] Karthikeyan, K., and Kumar, A. (2017). Paederus dermatitis. Indian J Dermatol Venereol Leprol. 83(4): 424.

[2] Rook, A., Wilkinson, D.S., Ebling, F.T.G.E. (1992). Diseases caused by arthropods and other noxious animals. In: Champion RH, Burton JL, Ebling ETGE, eds. Textbook of Dermatology. London: Blackwell Scientific.

[3] Qadir, S.R., Raza, N., and Rahman SB. (2006). Paederus dermatitis in Sierra Leone. Dermatol Online J. 12(7): 9.

[4] Ahmed, MS., Boraei, HA., and Rakha, OM. (2013). Histopathological characterization of induced Paederus dermatitis caused by Egyptian rove beetles (Paederus alfierii). Beni Suef Univ J Basic Appl Sci., 2(2): 108-113.

[5] Al-Basheer, M., Hijazi, M., and Dama, T. (2002). Blister beetle dermatosis. Report of 43 cases in a military unit in Eritrea. J Res Med Sci., 9(2): 40e2.

[6] Davalos, V., Luguna-Torres, V.A., and Uaman, A. (2002). Epidemic dermatitis by Paederus irritans in Piura, Peru in 1999, related to the El-nino phenomenon. Rev Soc Bras Med Trop., 35(1):23e8.

[7] Ebrahimzadeh, M.A., Rafati, M.R., Damchi, M., Golpur, M., and Fathiazad, F. (2014). Treatment of paederus dermatitis with Sambucus ebulus lotion. Iran J Pharm Res., 13(3): 1065 .

[8] Piel, J., Höfer, I., and Hui, D. (2004). Evidence for a symbiosis island involved in horizontal acquisition of pederin biosynthetic capabilities by the bacterial symbiont of Paederus fuscipes beetles. Int J Bacteriol. 186(5): 1280-1286. 
[9] Mammino, J.J. (2011). Paederus dermatitis: an outbreak on a medical mission boat in the Amazon. J Clin Aesthet Dermatol. 4: 44-6. Cameron, M. (1931). Coleoptera Staphylinidae. The Fauna of British India including Ceylon and Burma, Vol. z. London: Taylor and Francis, 1832-1905.

[10] Cameron, M. (1931). Coleoptera Staphylinidae. The Fauna of British India including Ceylon and Burma, Vol. z. London: Taylor and Francis, 1832-1905.

[11] Frank, J.H., and Kanamitsu, K. (1987). Paederus, Sensu Lato (Coleoptera: Staphylinidae): natural history and medical importance. J Med Entomol. 24: 155-191.

[12] Oyedeji, O.A., Adebami, O.J., and Oyedeji, G.A. (2006). Linear dermatitis following contact with the rove beetle in Nigerians: a report of 2 cases. Int J Trop Med. 3(1).

[13] Maryam, S., Fadzly, N., Amirul, A.A.A., and Zuharah, W.F. (2017). Attraction factors for Paederus fuscipes dispersal, a vector of Paederus dermatitis towards human residential premises. Rev Inst Med Trop Sao Paulo. 59.

[14] Bong, LJ., Neoh, K.B., Jaal, Z., and Lee, C.Y. (2013). Influence of temperature on survival and water relations of Paederus fuscipes (Coleoptera: Staphylinidae). J Med Entomol 50: 1003-13.

[15] Davidson, S.A., Norton, S.A., Carder, M.C., and Debboun, M. (2009). Outbreak of dermatitis linearis caused by Paederus ilsae and Paederus iliensis (Coleoptera: Staphylinidae) at a military base in Iraq. US Army Med Dep J., 6-15.

[16] Uzunoğlu, E., Oguz, I.D., Kir, B., et al. (2017). Clinical and epidemiological features of Paederus dermatitis among nut farm workers in Turkey. Am J Trop Med Hyg., 96(2): 483487.

[17] Veraldi, S., Cuka, E., Chiaratti, A., et al. (2013). Paederus fuscipes dermatitis: a report of nine cases observed in Italy and review of the literature. Eur J Dermatol., 23: 387-391.

[18] Kamaladasa, S.D., Perera, W.D.H., and Weeratunge, L. (1997). An outbreak of Paederus dermatitis in a suburban hospital in Sri Lanka. Int J Dermatol., 36(1): 34-36.

[19] Huang, C., Liu, Y., Yang, J., Tian, J., Yang, L., and Zhang, J., et al. (2009). An outbreak of 268 cases of Paederus dermatitis in a toy-building factory in central China. Int $J$ Dermatol. 48: 128-31.

[20] Rahmah, E., and Norjaiza, M.A. (2008). An outbreak of Paederus dermatitis in a primary school, Terengganu, Malaysia. 30(1): 53-56.

[21] Pedgley, D.E. (1982). Windborne pests and diseases: meteorology of airborne organisms. Chichester: Ellis Horwood. 109(460): 438-439.

[22] Gopal, K.V. (2014). Paederus dermatitis: a clinical, epidemiological and therapeutic study of 417 cases. J Evol Med Dent Sci. 3: 4736-43.

[23] Haddad, VJr., Cardoso, J.L., Lupi, O., and Tyring, S.K. (2012). Tropical dermatology: Venomous arthropods and human skin: Part I. Insecta. J Am Acad Dermatol. 67: 331. 
[24] Singh, G., Yousuf, Ali S. (2007). Paederus dermatitis. Indian J Dermatol Venereol Leprol., 73:13-5.

[25] Zargari, O., Kimyai-Asadi, A., Fathalikhani, F., et al. (2003). Paederus dermatitis in northern Iran: a report of 156 cases. Int J Dermatol. 42: 608-12.

[26] Assaf, M., Nofal, E., Nofal, A., Assar, O., and Azmy, A. (2010). Paederus dermatitis in Egypt: a clinicopathological and ultrastructural study. J Eur Acad Dermatol Venereol., 24(10): 1197-1201.

[27] Williams, A.N. (1993). Rove beetle blistering- (Nairobi Eye). J R Army Med Corps., 139:17-9.

[28] Ali, A., Sujitha K, Devika, T., et al. (2013). A study on Paederus dermatitis outbreak in a suburban teaching research hospital, Kanchipuram, India. Med Sci., 2(3): 764-769 